2008-07-01

\title{
Cognitive consequences of perceiving social exclusion
}

\author{
Wyer, NA
}

http://hdl.handle.net/10026.1/2951

10.1016/j.jesp.2008.03.002

Journal of Experimental Social Psychology

All content in PEARL is protected by copyright law. Author manuscripts are made available in accordance with publisher policies. Please cite only the published version using the details provided on the item record or document. In the absence of an open licence (e.g. Creative Commons), permissions for further reuse of content should be sought from the publisher or author. 


\title{
Cognitive consequences of perceiving social exclusion
}

\author{
Natalie A. Wyer \\ School of Psychology, University of Plymouth, Drake Circus, Plymouth PL4 8AA, UK
}

A R T I C L E I N F O

Article history:

Received 20 July 2007

Revised 4 March 2008

Available online 21 March 2008

\section{Keywords:}

Social exclusion

Relationship representation

Categorization

\begin{abstract}
A B S T R A C T
Although a great deal is now known about how people mentally represent individuals and groups, less attention has been paid to the question of how interpersonal relationships are represented in memory. Drawing on principles of categorization, this paper reports an investigation into how we mentally represent the relationships of others. In three experiments, evidence for assimilation effects following social exclusion (and subsequent categorization) is found. Experiment 1 uses a judgment paradigm to demonstrate that social exclusion influences the perception of interpersonal closeness. Experiments 2 and 3 employ a memory confusion paradigm to establish that representations of relationship partners are assimilated following the exclusion of a third party.
\end{abstract}

(c) 2008 Elsevier Inc. All rights reserved.

\section{Introduction}

Human nature is inherently social, but it is not indiscriminately so. As people navigate through their social lives, they embrace some relationships and forego others. As social perceivers, we are aware of this selectivity. We know that, to the extent that they are able to do so, people pick and choose the individuals with whom they develop relationships. Because few people have an infinite capacity for investing time and energy in new social relations, being selective in building one's social network is a necessity for most humans.

One by-product of being socially selective is that people must, at times, reject potential relationships and exclude prospective relationship partners. How do we, as social perceivers, interpret and represent the social relations that result from the inclusion of some people and exclusion of others? A long tradition of research has examined how we mentally represent individuals and groups (Hamilton \& Sherman, 1996; Srull \& Wyer, 1989). Surprisingly, there has been comparatively little research into the question of how we process information about the social relationships of others.

From the perspective of social perceivers, the ability to identify the nature of others' social relationships is critical. Knowledge regarding others' social relations allows perceivers to more accurately predict the consequences of their behavior. If Jeff knows that Jill has a relationship with Jack, but mistakenly perceives it as a platonic friendship, he may erroneously conclude that Jill is receptive to his romantic overtures. Similarly, if Keith is angry with Karl, but knows that Karl's good friend is Kevin, a 200-pound bodybuilder, he may sensibly decline to confront Karl.

The way in which we understand others' relationships was recognized, in earlier years, as an important issue within social per-

E-mail address: natalie.wyer@plymouth.ac.uk ception. Heider (1946) suggested that people are inclined to perceive balance in social relations. Given a triad of persons (Anna, Barbara, and Caroline) if Anna has positive relationships with both Barbara and Caroline, people tend to assume a positive relationship between Barbara and Caroline as well. However, if Anna is positively associated with Barbara but negatively associated with Caroline, people assume a negative relationship between Barbara and Caroline. Thus, Heider's balance theory suggests that people are motivated to perceive social relationships as consistent with each other. Although this important observation is now widely accepted (Abelson, 1983), little has been done to further our understanding of how we mentally represent the social relationships of others.

One important exception to this rule is a model proposed by Sedikides, Olsen, and Reis (1993) in which they conceptualized relationships as natural categories. This conceptualization implies that social perceivers may use relationships to organize information in memory, just as they do for group-related information. In building the case for relationships as categories, Sedikides et al. (1993) reported a series of experiments which demonstrated that participants' recall of information they had learned about a number of individuals was organized around relationships-items associated with two people were more likely to be retrieved in sequence if the individuals were identified as members of a married couple than if they were identified as acquaintances, fans of the same football team, or randomly paired individuals. Moreover, participants were more likely mistakenly attribute information about one member of a couple to the other member than they were to make similar errors about individuals who were not identified as belonging to the same couple.

The results reported by Sedikides et al. (1993) suggest that information about close or interdependent relationships may be processed in a similar manner as information about other types of categories. In their studies, the perceived closeness of relationships was manipulated by identifying some individuals as married cou- 
ples. However, as noted by the authors, other cues may be equally important in determining whether members of a relationship are viewed in categorical terms: 'the interesting question here is not which characteristics define a close relationship, but rather which qualities lead observers to spontaneously connect relationship partners in memory' (p. 81). In other words, what leads social perceivers to treat some relationships (but not others) as categories?

\section{Properties of categorization}

When it comes to social categories, the way a target group is perceived is profoundly affected by the presence of other groups in the same social context. For example, the salience of intergroup comparisons may lead to increases in the perception that members of the same group are similar (Castano \& Yzerbyt, 1998; Corneille \& Judd, 1999; Rothbart, Davis-Stitt, \& Hill, 1997) and that members of different groups are dissimilar (Doosje, Haslam, Spears, Oakes, \& Koomen, 1998; Judd \& Park, 1993).

Such effects can be attributed to the operation of two related processes that result from categorization (Corneille \& Judd, 1999; Tajfel \& Turner, 1986; Taylor, Fiske, Etcoff, \& Ruderman, 1978; Turner, Hogg, Oakes, Reicher, \& Wetherell, 1987). First, categorizing others into groups leads to between-group contrast-that is, members of one group are viewed as more different from members of another group than they would in the absence of categorization (Doise, 1990; Long \& Manstead, 1997). Second, categorization leads to within-group assimilation-that is, members of the same group are seen as more similar to each other than if they had not been categorized (Simon \& Brown, 1987). Research on these categorization effects has, logically enough, been limited to the study of social groups-groups varying in size but typically consisting of at least four individuals (Taylor et al., 1978) or of indeterminate size (Jetten, Spears, \& Postmes, 2004). Yet, the same processes of assimilation and contrast may equally apply to interpersonal relationships in which categorization occurs.

\section{Social exclusion and categorization}

It is proposed here that social exclusion is an important cue that may determine whether a relationship is viewed in categorical terms. Although perceivers may categorize relationship partners on the basis of a number of cues (e.g., an explicit commitment to each other, see Sedikides et al., 1993), social exclusion may be among the most salient. The observation that members of a relationship have actively excluded others may serve to highlight the boundary between outsiders and the relationship itself. Just as the mere presence of a second group within a social context influences the extent to which a target group is subject to categorization effects (i.e., assimilation and contrast), the mere presence of non-members of a relationship may similarly lead to relationship members being perceived as a category.

Although this possibility has not yet been explored in the context of perceptions of interpersonal relationships, recent theorizing by Pickett and Brewer (2005) supports the view that exclusion leads to categorization effects when it comes to intergroup relationships. In particular, Pickett and Brewer suggest that an important reason that some members of a group may socially exclude others is to maximize their own feelings of inclusion in the group. The exclusion of other 'marginal' group members allows individuals to assert their own established position within the group (see also Castano, Paladino, Coull, \& Yzerbyt, 2002). Similarly, individuals who identify with a social group are more likely exclude others from the group than are those who belong, but do not identify with the same group (Castano, Yzerbyt, Bourguignon, \& Seron, 2002). This 'in-group over-exclusion effect' (Yzerbyt, Leyens, \& Bellour, 1995 ) refers to the tendency to exclude from the in-group any indi- viduals whose group membership is in doubt and is thought to be linked to in-group identification (see also Blascovich, Wyer, Swart, \& Kibler, 1997). Thus, in managing their perceptions of an important in-group, individuals may use social exclusion as a way of maximizing in-group solidarity and distinctiveness from other groups. In other words, social exclusion contributes to withingroup assimilation and between-group contrast.

Social exclusion plays an important role in drawing group boundaries and hence in determining how social groups are perceived. When it comes to dyadic relationships, exclusion may operate in a similar way. Current theories do not address the possibility that categorization effects occur when social exclusion takes place on an individual rather than a group level. There are, however, reasons to suppose that contrast and assimilation effects may follow from social exclusion. For example, according to Aron's Self-Expansion Model (Aron \& Aron, 1986), individuals in close relationships develop overlapping (or assimilated) representations of themselves and their relationship partners (a process referred to as self-expansion). While SEM does not go into detail about the cognitive mechanisms through which another person is assimilated to the self, research stemming from the model has identified factors associated with self-expansion. For example, shared experiences that are novel (Aron, Norman, Aron, McKenna, \& Heyman, 2000), humorous (Fraley \& Aron, 2004) or defined by mutual self-disclosure (Aron, Melinat, Aron, Vallone, \& Bator, 1997) are all associated with greater interpersonal closeness. What these studies have in common is that factors that lead to increased feelings of closeness are those that increase the perception of uniquely shared knowledge and experiences.

Why does uniquely shared experience generate interpersonal closeness, whereas more mundane or commonplace experiences do not (Aron et al., 2000)? One possibility is that awareness that a shared experience is unique creates a category boundary. That is, those who have shared an unusual experience may view themselves as members of a different category than those who have not had that experience. Two strangers who meet in Chicago and learn that they were on the same island in Thailand during the 2004 tsunami may feel a bond based on that experience, particularly when surrounded millions of people who do not share it. By spontaneously categorizing people into those who shared the experience and those who did not, the tsunami survivors find themselves within the category boundary, and therefore may assimilate each other into their self-concepts.

Likewise, sharing personal information (e.g., self-disclosure) has been identified as a key factor contributing to closer interpersonal relationships (e.g., Altman \& Taylor, 1973; Collins \& Miller, 1994). Indeed, research by Aron et al. (1997) suggests that self-disclosure plays a causal role in producing feelings of closeness between individuals with no prior connection to each other. Conveying personal information about others (i.e., gossip) plays a similar role in building social bonds (e.g., Fine, 1977). As when people share unusual experiences, sharing personal information that is not commonly known may lead to categorization based on uniquely shared knowledge.

Thus, categorization may be critical in producing effects described by SEM. Perceiving a relationship as unique may lead to categorization, which in turn results in assimilation of individuals within the relationship. In the preceding examples, 'outsiders' are not explicitly excluded from the relationship, but a distinction is drawn between those within the relationship and those outside of it. If such distinctions produce assimilation between self and other representations, the extent of assimilation should be even greater when exclusion is intentional and explicit.

This analysis may apply equally well to the issue of how we represent social relationships to which we do not belong. When social perceivers observe that social exclusion has occurred in a relationship, they may draw a category boundary between the members of 
the relationship that have engaged in the exclusion, and the individual(s) whom they have excluded. As a result of drawing this boundary, perceivers may form a representation of exclusive relationships such that their members are assimilated to each other. Assimilation may influence subjective judgments such that members of exclusive relationship are believed to be closer or more similar. It may also influence information processing such that perceivers process information about members of exclusive relationships in more similar ways.

\section{Experiment overview \& hypotheses}

Three studies are described below that investigate these possibilities. In Experiment 1, participants were presented with brief scenarios, each describing an encounter among a number of people. In some of these encounters, two individuals shared personal information with each other while explicitly withholding that information from a third person. Thus, in some instances, participants learned that the relationship being depicted was characterized by social exclusion. In other scenarios, no explicit exclusion took place. Participants' subjective perceptions of these relationships were then assessed. In Experiments 2 and 3, cognitive assimilation and contrast effects were explored more directly using a memory confusion paradigm. In all cases, social exclusion was expected to result in assimilation, as evidenced by judgments of relationship closeness (Experiment 1 ) and by the extent of differentiation between relationship members (Experiments 2 and 3 ).

\section{Experiment 1}

In many social contexts, individuals learn about and form impressions of a wide variety of targets: other individuals, other groups, as well as others' friendships or close relationships. As suggested above, the representations that one builds of others' relationships may be influenced by the social exclusiveness of their interactions. The ability to identify the nature of others' relationships is important because it provides information on a number of issues. Is the relationship permeable (e.g., is it possible to join the relationship)? Can one member of the relationship be expected to share information or characteristics (e.g., knowledge, goals, or motives) with the other? Can one relationship partner be held responsible for the acts of the other? The ability to make accurate inferences about the closeness of a particular relationship helps to inform all of these questions.

In Experiment 1, the effect of social exclusion on the perception of social relationships was investigated by exposing participants to brief scenarios about a number of social relationships, some of which were characterized by social exclusion. According to the reasoning introduced above, exclusive relationships should be viewed as closer than non-exclusive ones. In addition, to assess the effect of exclusion on inferences other than closeness, participants were asked to make a number of additional judgments following each scenario. In particular, participants were asked to judge the extent to which the relationship was unique and reciprocal, and the extent to which members of the relationship were similar in terms of their personalities and backgrounds. To the extent that social exclusion is a cue to view a relationship as a category, members of exclusive relationships should be viewed as closer and more similar, and the relationship should be characterized as more reciprocal and more unique.

\section{Method}

\section{Participants}

Sixty students (20 males, 40 females) at the Free University of Amsterdam (NL) participated in this study in exchange for $€ 2.50$ (approximately \$3.50). Participants were tested individually in isolated cubicles. The experiment took approximately $10-15 \mathrm{~min}$ to complete.

\section{Design and materials}

The study involved a within-participants design, in which participants were exposed to three exclusion conditions (exclusion, inclusion, or control). Twelve scenarios were constructed for use in this study. ${ }^{1}$ Each scenario depicted an interaction among two or three individuals of the same sex (half of the scenarios in each condition portrayed female targets while the other half portrayed male targets). Different forenames were used in each scenario, so that each interaction would be perceived as independent of the others. In the control condition, one of the people (Target 1 or T1) conveyed personal information with one other person (Target 2 or T2). In the exclusion condition, $\mathrm{T} 1$ conveyed the same information to T2, while ensuring that a third person (Target 3 or T3) was not present during the interaction. In the inclusion condition, T1 conveyed the information to both $\mathrm{T} 2$ and T3. The specific behaviors were counterbalanced such that, across participants, all behaviors appeared in exclusion, inclusion, and control conditions and involved both male and female protagonists.

\section{Procedure}

Participants were introduced to a study on how people perceive the relationships of others. They were informed that they would read about a number of different relationships, and that they would make judgments about the nature of each relationship. Participants then read each of the 12 scenarios, the order of which was randomized. After each scenario, participants were asked to judge the degree of closeness between T1 and T2 and between T1 and T3. They were then asked to judge the relationship between T1 and T2 on a number of dimensions. Specifically, participants rated the likelihood that $\mathrm{T} 1$ would share the same information with others (uniqueness), the likelihood that T2 would share similar information with $\mathrm{T} 1$ (reciprocity), and the similarity of $\mathrm{T} 1$ and $\mathrm{T} 2$ in terms of their personalities and backgrounds. Ratings were made on a 9point scale $(1=$ not at all to $9=$ extremely $)$.

\section{Results $^{2}$}

\section{Closeness of T1 and T3 (manipulation check)}

Participants' ratings of the closeness of T1 and T3 were analyzed using a paired samples $t$-test in which exclusion and inclusion conditions were compared. The analysis indicated a significant difference such that participants rated the two targets as significantly closer when T3 was included in the interaction $(M=6.34$, $s=0.92)$ than he or she was excluded $(M=3.90, s=1.26)$, $t(59)=11.75, p<.001 d=2.21$.

\section{Closeness of $T 1$ and $T 2$}

The critical dependent measure was participants' perceptions of the closeness of T1 and T2. A repeated-measures Analysis of Variance (ANOVA) was conducted to assess the effect of exclusion on perceived T1-T2 closeness. This analysis revealed a significant

\footnotetext{
${ }^{1}$ For exploratory purposes, the scenarios included instances where the communication shared between targets concerned one of the targets him/herself (i.e., selfdisclosure) as well as instances where it involved a third party (i.e., gossip). These variations had no significant effects nor did they interact with any other variable. Hence, they are not discussed here.

2 Preliminary analyses involving both participant gender and target gender were carried out for this study as well as all subsequent studies. These analyses produced no significant main effects of gender (either participants' or targets') or interactions involving gender (either participants' or targets')
} 
Table 1

Mean ratings of T1-T2 relationship closeness, uniqueness, reciprocity and similarity (Experiment 1)

\begin{tabular}{lclc}
\hline & Exclusion & Control & Inclusion \\
\hline Closeness & $7.02^{\mathrm{a}}(0.86)$ & $6.56^{\mathrm{b}}(0.87)$ & $6.33^{\mathrm{b}}(0.91)$ \\
Uniqueness & $4.61^{\mathrm{a}}(1.28)$ & $5.72^{\mathrm{b}}(1.21)$ & $6.05^{\mathrm{b}}(1.26)$ \\
Reciprocity & $6.24^{\mathrm{a}}(0.94)$ & $6.06^{\mathrm{ab}}(1.19)$ & $5.83^{\mathrm{b}}(0.97)$ \\
Similarity & $6.15^{\mathrm{a}}(0.97)$ & $5.91^{\mathrm{b}}(1.00)$ & $5.78^{\mathrm{b}}(0.99)$
\end{tabular}

Higher numbers indicated greater closeness, reciprocity, and similarity and less uniqueness. Means within a row marked with different superscripts are significantly different from each other $(p<.05)$.

main effect of exclusion condition, $F(2,118)=16.04, p<.001$, $\eta_{\mathrm{p}}{ }^{2}=.21 .^{3}$ Follow-up paired samples $t$-tests indicated that participants rated the T1-T2 relationship as significantly closer in the exclusion condition than in either the control condition, $t(59)=4.07, p<.001, d=.53$ or the inclusion condition, $t(59)=5.73$, $p<.001, d=.78$, the difference between which was marginally significant, $t(59)=1.70, p<.10, d=.26$. See Table 1 for means and standard deviations.

\section{Uniqueness, reciprocity, and similarity}

In addition to rating the closeness of the T1-T2 relationship, participants judged the uniqueness and reciprocity of the relationship, and the similarity of the two interactants. Each of these ratings was examined using the same analytic strategy described above. In each case, there was a significant main effect of exclusion such that higher ratings were obtained in the exclusion condition than in the inclusion or control conditions, smallest $F(2$, $118)=3.85, p<.03, \eta_{\mathrm{p}}{ }^{2}=.06$ (see Table 1$)$.

In addition, indices of exclusion and inclusion effects on similarity, uniqueness, and reciprocity ratings were calculated by subtracting ratings in the control condition from those in the exclusion and inclusion conditions, respectively. These indices were entered as covariates in a repeated-measures ANCOVA comparing closeness ratings among the three exclusion conditions. Although inclusion effects on uniqueness $(F(2,106)=5.38$, $\left.p<.01 . \quad \eta_{\mathrm{p}}{ }^{2}=.09\right)$ and reciprocity $(F(2,106)=2.71, \quad p<.08$, $\left.\eta_{\mathrm{p}}{ }^{2}=.05\right)$ emerged as significant or marginally significant covariates, the main effect of exclusion condition remained significant even with all covariates included in the analysis, $F(2,106)=3.37$, $p<.04, \eta_{\mathrm{p}}{ }^{2}=.06$. Importantly the within-subjects contrast comparing the exclusion condition against the inclusion and control conditions was also significant, $F(1,53)=6.29, p<.02, \eta_{\mathrm{p}}{ }^{2}=.11$.

\section{Discussion}

The results of Experiment 1 supported the hypothesis that social exclusion is used as a cue to treat relationships as categories-participants judged exclusive relationships to be significantly closer than non-exclusive relationships. Thus, these results support the proposal that social exclusion leads to categorization-based assimilation of relationship partners. Further evidence is provided by the finding that social exclusion influences perceptions of relationship reciprocity and uniqueness, and judgments of similarity between the relationship partners. These results are consistent with the view that exclusion affects perceived closeness by encouraging perceivers to categorize T1 and T2 into a separate category than T3 (suggested by higher sim-

\footnotetext{
${ }^{3}$ Although the goal of brevity precludes their full reporting, it is worth noting that the effect of exclusion on perceived closeness has been replicated in three other experiments including a further 170 participants, $F$ s $=19.55$ to 44.00 , all $p$ 's $<.001 ; d$ $=.46$ to .59 (average $d=.53$ ).
}

ilarity ratings) and consequently assimilating T1 and T2 (suggested by higher ratings of the relationship's uniqueness and reciprocity).

While the results of Experiment 1 are consistent with the framework presented earlier, a number of limitations must be addressed. First, a potential criticism of Experiment 1 concerns its reliance on self-report measures obtained from a within-participants design. Because of the design, explicit comparisons among scenarios were possible, which raises the possibility that demand characteristics contributed to the results.

In addition, although the judgment measures used in Experiment 1 are consistent with the premise that social exclusion encourages categorization, resulting in increases in perceived relationship closeness, they do not provide a direct investigation of how relationship partners are mentally represented. The finding that partners are perceived as closer under exclusion conditions than under inclusion or control conditions does not necessarily indicate that participants' representations of them have been assimilated.

Moreover, if assimilation did occur, it is still possible that factors other than exclusion per se were responsible for the finding that T1 and T2 were perceived as closer when they excluded T3. For example, participants may have formed relatively negative evaluations of T1 and T2 because they perpetrated the exclusion of T3 (towards whom they may have reacted with greater sympathy). Although no data relating to participants' evaluations of the targets are available to address the possibility, it may be that such differing evaluations of T1 and T2 versus T3 contributed to categorization and hence influenced the perceived closeness of the three targets.

Experiments $2 \mathrm{a}$ and $2 \mathrm{~b}$ were conducted to address concerns about alternative interpretations of the data (by using a fully between-participants design) as well as to provide a more direct measure of how people mentally represent exclusive and nonexclusive relationships.

\section{Experiment 2}

If one's mental representations of two people are assimilated, one should be less likely to differentiate between information related to those people. For example, Mashek, Aron, and Boncimino (2003), asked participants to judge three different lists of personality trait words. In each list, they judged whether the trait described either themselves, a close other, or a familiar but non-close other. Later, participants were presented with words from all three lists and were asked to indicate the person for whom they had judged each of them. In analyzing participants' errors, Mashek and colleagues observed that participants were most likely to make errors in which words judged for the self and words judged for the close other were confused.

Experiment 2 adapted the paradigm used by Mashek et al (2003; see also Sedikides et al., 1993) to assess whether representations of two people in a relationship are less differentiated (i.e., assimilated) when the relationship socially excludes others. If one's mental representations of two people in a relationship are assimilated, one should be more likely to confuse information encoded in relation to one relationship partner for that encoded in relation to the other. According to the framework outlined earlier, this should be the case when perceivers encode information about two individuals who exclude a third person (e.g., T1 and T2 in the previous experiment).

\section{Experiment $2 a$}

If, as expected, participants make more memory confusions involving members of socially exclusive relationships than members of non-exclusive relationships, this would provide direct evi- 
dence of assimilation and support the view that exclusion is a cue used in categorization. However, at least one competing account must be considered. Specifically, social exclusion, as manipulated in Experiment 1, is partially confounded with shared distinctiveness. In the first experiment, two targets in an exclusive relationship share distinctive features (e.g., the fact that they engaged in exclusion and the fact that they have information unknown by others) that are not shared by the excluded target.

These distinctive features may contribute to assimilation effects in two ways. First, prior research (e.g., Nelson \& Miller, 1995) suggests that perceivers use distinctive features as a basis for categorization. Thus, participants may categorize $\mathrm{T} 1$ and $\mathrm{T} 2$ because they share distinctive features, which may contribute to assimilation effects. According to this view, the observation that two targets share any distinctive feature is sufficient to elicit categorization-the feature need not have anything to do with social exclusion. Thus, shared distinctiveness-and not social exclusion-may result in categorization.

A second way in which shared distinctiveness may affect assimilation is by increasing perceived similarity among the relationship partners after they have been categorized. According to Tversky's (1977) model of similarity, the greater the number of distinctive features shared among category members, the greater the perceived similarity will be. This view suggests that targets who shared distinctive features because of circumstances having nothing to do with exclusion might be viewed as more similar, which may have contributed to the results found in the first two experiments. Thus, shared distinctiveness-and not social exclusionmay lead to assimilation effects once categorization had occurred.

The possibility that shared distinctiveness or similarity alone leads to assimilation effects is argued against by the results of Experiment 1 , which indicated that target similarity was not a significant covariate, nor did target similarity, relationship reciprocity, or relationship uniqueness account for the effects of exclusion on perceived closeness. When all of these variables were controlled for, the effect of exclusion on perceived closeness remained significant.

To provide further evidence that exclusion produces unique effects on relationship representation beyond that accounted for by shared distinctiveness, Experiment 2a includes a direct comparison of an exclusion condition with one in which targets share distinctive features not related to exclusion. If categorization and assimilation are due to shared distinctiveness rather than exclusion per $s e$, then assimilation effects should also be found in this condition.

A second goal of Experiment 2a is to investigate the role of intention in producing exclusion-based categorization. Experiment 1 utilized a manipulation that involved intentional acts of social exclusion. Yet, there may be instances where social exclusion occurs due to situational factors rather than the explicit intentions of those who engage in it. The preceding analysis implies that while intentionality may make exclusion more salient, it may not be strictly necessary for exclusion-based categorization to occur. To examine the role of intention more closely, a further condition was included in Experiment 2a in which two targets exclude a third person as the result of situational factors.

\section{Method}

\section{Participants}

Eighty members of the Plymouth (UK) community (29 males and 51 females) participated in this and an unrelated experiment in exchange for $£ 3$ (approximately \$6). The experiment lasted approximately $15 \mathrm{~min}$.

\section{Design and procedure}

The experiment employed a between-participants design, in which five groups of participants received different information about a social relationship (inclusion, intentional exclusion, unintentional exclusion, shared distinctiveness, or control).

Upon arriving at the laboratory, participants were informed that they would be taking part in a study on how people perceive social relationships. Participants were initially introduced to three people, Anna, Janine, and Sandra (hereafter T1, T2, and T3) who were described as members of the same social group. Participants were randomly assigned to one of five relationship information conditions. Participants in all conditions learned that the three targets belonged to a student group and had known each other for one year. Those in the control condition were given no further information. Participants in the shared distinctiveness condition also learned that, by coincidence, T1 and T2 shared the same birthday. Participants in the other three conditions learned that T1 and T2 spend a lot of time together discussing events from their own lives as well as the lives of others in their group. Those in the inclusion condition learned that T1 and T2 often tried to include T3 in their discussions. Those in the intentional exclusion condition learned that T1 and T2 always made a point of keeping T3 out of their discussions. Those in the unintentional exclusion condition learned that $\mathrm{T} 1$ and $\mathrm{T} 2$ wanted to include $\mathrm{T} 3$ in their discussions, but because T3 worked and lived out of town, she was never present during their discussions.

After reading the information about the relationships among the three targets, participants were informed that they would form impressions of two of the three targets ( $\mathrm{T} 1$ and $\mathrm{T} 2$ ) by learning a series of personality traits that described each of them. Participants were then presented with a list of 20 personality trait words that described $\mathrm{T} 1$ and a second list of 20 trait words that described T2. All words were randomly selected from Anderson's (1968) list of personality trait words. The order of the T1 and T2 lists was counterbalanced. After viewing the two lists, participants were asked to take a few minutes to think about their impressions of the two individuals. Participants then received instructions for a recognition task. Participants were presented with the 40 personality trait words that had been presented during the preceding two lists as well as with 40 trait words that had not been previously presented. Participants were instructed to indicate whether each word had described T1 or T2, or had not been presented at all, by pressing one of two keys on the computer keyboard.

\section{Results}

Words presented during the recognition task can be classified as 'Target 1' (words that described T1), 'Target 2' (words that described T2), and 'new' (words that were not presented at all). Thus, each response can be classified as either a 'hit' (correctly identifying the target who had been described by the word), a 'confusion' (attributing a word that had described one target to the other target), a 'miss' (failing to recognize that a word had described either target), a 'false alarm' (indicating that a new word had described either of the two targets) or a 'correct rejection' (correctly indicating that a new word had not been presented). Because misses are the complement of the combination of hits and confusions, and similarly correct rejections are the complement of false alarms, only hits, confusions, and false alarms were analyzed.

Memory confusion errors were calculated as the proportion of times (out of a total of 40 trials) that a trait that had been presented for one target was attributed to the other. A one-way ANOVA comparing the five conditions revealed a significant main effect of relationship information, $F(4,79)=4.41, p<01, \eta_{\mathrm{p}}{ }^{2}=.19$. Planned comparisons were conducted to compare the intentional exclusion condition to each of the other four conditions. These analyses indicated that whereas confusion rates did not significantly differ in the intentional exclusion and unintentional exclusion conditions, $t(75)=.65, n s, d=.17$, rates were significantly higher in the 
Table 2

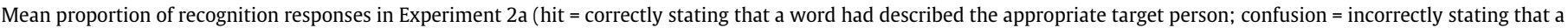
word had described the inappropriate target person; false alarm = incorrectly stating that a non-presented word had described either target person)

\begin{tabular}{|c|c|c|c|c|c|}
\hline & Intentional exclusion & Unintentional exclusion & Shared distinctiveness & Inclusion & No information \\
\hline Hit & $0.46^{\mathrm{ab}}(0.15)$ & $0.37^{\mathrm{b}}(0.17)$ & $0.43^{\mathrm{ab}}(0.14)$ & $0.43^{\mathrm{ab}}(0.08)$ & $0.53^{\mathrm{a}}(0.17)$ \\
\hline Confusion & $0.34^{\mathrm{a}}(0.10)$ & $0.32^{\mathrm{a}}(0.13)$ & $0.28^{\mathrm{ab}}(0.10)$ & $0.23^{\mathrm{b}}(0.08)$ & $0.23^{\mathrm{b}}(0.07)$ \\
\hline False Alarm & $0.37^{\mathrm{a}}(0.15)$ & $0.38^{\mathrm{a}}(0.21)$ & $0.30^{\mathrm{a}}(0.18)$ & $0.26^{\mathrm{a}}(0.13)$ & $0.27^{\mathrm{a}}(0.14)$ \\
\hline
\end{tabular}

Means within a row marked with different superscripts are significantly different $(p<.05)$.

intentional exclusion condition than in either the no information $(t(75)=3.19, p<.01, d=1.27)$ or inclusion $(t(75)=3.32, p<.01$, $d=1.21$ ) conditions, and marginally higher than in the shared distinctiveness condition, $t(75)=1.84, p<.07, d=.60$.

Subsequent analyses indicated that exclusion condition had a marginally significant effect on hit rates, $F(4,79)=2.37, p=.06$, $\eta_{\mathrm{p}}{ }^{2}=.11$ but a non-significant effect on false alarms $F(4$, $\left.79)=1.98, p>.10, \eta_{\mathrm{p}}{ }^{2}=.10\right)$. The complete set of means and standard deviations are presented in Table 2.

\section{Experiment $2 b$}

As noted above, participants in the distinctiveness condition differed only marginally in their confusion rates (although the exclusion condition was significantly different from the control condition whereas the distinctiveness condition was not). Thus, it is not possible to completely rule out the possibility that perceptions of shared distinctiveness contributed to the exclusion effects reported in Experiment 2a. The purpose of Experiment 2b was to provide an explicit test of the extent to which perceptions of shared distinctiveness mediate the effect of exclusion on assimilation as assessed by memory confusions.

\section{Method}

\section{Participants}

Twenty-two members of the Plymouth (UK) community (14 females, 8 males) took part in this and an unrelated experiment in exchange for $£ 3$ (approximately $\$ 6$ ).

\section{Design and procedure}

Experiment $2 \mathrm{~b}$ involved a two-group between-participants design. Participants were randomly assigned to either the exclusion or control condition. The procedures were identical to those described in Experiment 2a, with the exception that participants answered additional questions after the recognition task. Specifically, participants were asked to rate how unusual it is for two people to socially exclude another person, how meaningful social exclusion is to the people who do it, how similar T1 and T2 were to each other, and how unique the relationship between T1 and T2 was. All ratings were made on a 9 -point scale $(1=$ not at all, $9=$ very much).

\section{Results}

Memory confusions, hits, and false alarms were calculated as described in Experiment 2a. In order to assess whether the effects of exclusion on memory errors were replicated, a series of independent-samples $t$-tests were conducted. Of primary importance, participants in the exclusion condition made significantly more memory confusions $(M=.28, s=.16)$ than did those in the control condition $(M=.15, s=.09), t(20)=2.43, p<.03, d=1.00$. In addition, participants in the exclusion condition also produced fewer hits $(M=.45, s=.18)$ than did those in the control condition $(M=.65$, $s=.11), t(20)=3.12, p<.01, d=1.34$. However, there was no significant difference in false alarm rates, $t(20)=.54, n s, d=.24$.
In order to examine the role that perceptions of distinctiveness may have played in producing assimilation, an Analysis of Covariance (ANCOVA) was carried out in which participants' ratings of the unusualness and meaningfulness of social exclusion were entered as covariates. Neither covariate proved to be significant (largest $\left.F(1,22)=1.25, p>.25, \eta_{\mathrm{p}}{ }^{2}=.07\right)$. Moreover, the effect of exclusion condition remained significant, $F(1,22)=5.98, p<.03$, $\eta_{\mathrm{p}}{ }^{2}=.25$ ) when those covariates were added. A similar analysis was conducted using relationship-specific measures of shared distinctiveness (participants' ratings of how similar T1 and T2 were and of how unique their relationship was). Again, neither covariate was significant, largest $F(1,22)=1.31, p>.25, \eta_{\mathrm{p}}{ }^{2}=.02$, while the main effect of exclusion remained marginally significant, $F(1$, 22) $=3.82, p<.07, \eta_{\mathrm{p}}{ }^{2}=.23$.

\section{Discussion}

Experiments $2 \mathrm{a}$ and $2 \mathrm{~b}$ provided important clarifications of the results found in Experiment 1. First, they provide direct evidence that mental representations of individuals in relationships characterized by social exclusion are assimilated. Thus, while the results of Experiment 1 may have been clouded by the possibility of demand characteristics, that interpretation becomes less plausible in light of the memory confusion results found in Experiments 2a and $2 \mathrm{~b}$.

In addition, as noted earlier, an alternative interpretation of exclusion-based assimilation effects is that the responses of participants in the exclusion conditions were, in fact, the result of targets' sharing distinctive features rather than of exclusion per se. The results of Experiments $2 \mathrm{a}$ and $2 \mathrm{~b}$ do not support this interpretation. Participants in the exclusion condition made more memory confusions than participants in either the control or inclusion conditions. In contrast, participants in the shared distinctiveness condition produced no more memory confusions than did those in the control and inclusion conditions, as would be expected if categorization of T1 and T2 resulted from any indication of shared distinctiveness. Simply being similar on a distinctive dimension is not sufficient to produce categorization or assimilation effects. Indeed, although participants in the distinctiveness condition of Experiment 2a did not significantly differ from those in either the control/inclusion or the two exclusion conditions, the results of Experiment $2 \mathrm{~b}$ strongly suggest that perceptions of distinctiveness are not responsible for the observed exclusion effects. This finding is consistent with existing research on categorization (Murphy \& Medin, 1985; Nosofsky, 1986; Stangor, Lynch, Duan, \& Glass, 1992) which suggests that people are more likely to form and/or perceive categories when the potential basis for categorization is perceived as meaningful or diagnostic. In the present studies, acts of social exclusion are likely to be such meaningful and diagnostic cues to view targets in categorical ways. In contrast, although similarity is certainly an important factor influencing the categorization process under some circumstances (Tversky, 1977), it is not-by itself-enough to trigger categorization in the present context.

The results of Experiment 2a also demonstrate that exclusion need not be intentional for it to produce categorization effects. 
The difference in memory confusions produced by participants in the unintentional exclusion condition and those in the control and inclusion conditions did not reach significance. However, the results (in particular, the finding that unintentional and intentional exclusion led to similar levels of memory confusions) suggest that exclusion may produce categorization effects even when it results from situational factors rather than from the will of those who exclude.

The results of the shared distinctiveness and unintentional exclusion conditions, taken together, imply a more complex picture of social exclusion and categorization-based assimilation effects. In contrast to the alternative account suggested by other theories (e.g., Nelson \& Miller, 1995; Tversky, 1977), simply sharing distinctive features is not sufficient in this context to trigger categorization or to result in assimilation. Thus, social exclusion does appear to play a unique role in these processes. However, the results of this experiment also suggest that intentional or active exclusion may not be necessary to produce the effects observed in previous studies. Albeit to a lesser extent, unintended exclusion also resulted in an elevated level of memory confusions, suggesting that it, too, produces categorization and subsequent assimilation.

\section{Experiment 3}

While the results of Experiment 2 provided direct evidence that perceivers assimilate their impressions of individuals in socially exclusive relationships, they did not address the possibility of contrast between those and impressions of excluded individuals. The analysis offered earlier suggests that one's representation of a third person should be more differentiated (i.e., contrasted) when he or she is excluded from a relationship than when he or she is not explicitly excluded. To the extent that one's mental representations of two people are contrasted, one should be less likely to confuse information encoded in relation to one of those people for that encoded in relation to the other. This should occur when perceivers encode information about one of the two members of a relationship along with a third person who has been excluded (e.g., T1 and $\mathrm{T} 3$ in the previous experiments).

To test this hypothesis, participants were given information about two friends who either excluded a third person or not. Participants formed an impression of two targets (either the two friends, or one of the friends and the excluded person) by reading personality trait words that described each of them. After the trait lists were presented, participants performed a recognition task in which they identified whether each of the words had been presented in the description of one or the other target.

\section{Method}

\section{Participants}

One hundred and twenty students (51 male and 69 female) at the Free University of Amsterdam (NL) participated in this experiment in exchange for $€ 2.50$. The experiment lasted for approximately $15 \mathrm{~min}$.

\section{Design and procedures}

The experiment involved a between-participants design, in which participants were randomly assigned to one of three exclusion conditions (exclusion 1, exclusion 2, or control).

Upon arriving at the laboratory, participants were informed that they would be taking part in a study on how people perceive social relationships. Participants were initially introduced to three people, Anna, Janine, and Sandra (T1, T2, and T3) who were described as members of the same social group. Participants in the exclusion 1 and exclusion 2 conditions learned that $\mathrm{T} 1$ and $\mathrm{T} 2$ spent a lot of time together discussing events from their own or other group members' lives and that they always made sure that T3 was not present when they had these discussions. Participants in the control condition were not given this information.

Participants were then informed that they would form impressions of two of the individuals. Participants in the control and exclusion 1 conditions were to form an impression of $\mathrm{T} 1$ and $\mathrm{T} 2$ (i.e., the two targets who belonged to the central relationship), while those in the exclusion 2 condition were to form an impression of $\mathrm{T} 1$ and T3 (i.e., one target who belonged to the central relationship along with the target who was excluded from the relationship). Participants were presented with two lists of 20 trait words, each list describing one of the two targets. The order of the lists and the targets described by each were counterbalanced across participants. Within each list, the trait words were presented one at a time, for $2 \mathrm{~s}$ each (separated by a 1-s pause) on a computer screen, with the target's name remaining on the screen to the left of each word. After reading both lists, participants completed a brief distracter task after which they completed a recognition task similar to that described in Experiment 2a.

\section{Results}

Memory confusions, hits, and false alarms were calculated as described in Experiment 2a. To assess the extent to which participants differentiated between information learned about the two targets, confusions were analyzed using a one-way ANOVA in which exclusion condition was entered as the independent variable. This analysis yielded a significant main effect, $F(2$, $117)=11.19, p<.001, \eta_{\mathrm{p}}{ }^{2}=.16$. Planned contrasts confirmed that participants in the exclusion 1 condition made more memory confusions than did those in either the control condition, $t(117)=2.67$, $p<.01, d=.49$, or the exclusion 2 condition, $t(117)=4.72, p<.001$, $d=.87$, which also significantly differed from one another, $t(117)=2.04, p<.05, d=.38$. Means and standard deviations can be found in Table 3 .

Subsequent analyses indicated a further significant effect of exclusion condition on hits $(F(2,117)=5.71), p<.01, \eta_{\mathrm{p}}{ }^{2}=.09$, such that participants in the exclusion 1 condition produced a lower proportion of hits than those in the control, $t(117)=2.28, p<.03$, $d=2.28$, or exclusion 2 conditions, $t(117)=3.30 p<.01, d=.61$, which did not significantly differ, $t(117)=1.02, p>.30, d=.19$. This finding is, perhaps, not surprising in light of the fact that participants may have believed that target words had actually described the other target person. Given the absence of any effect of exclusion condition on false alarms, $F(2,117)=1.10, n s, \eta_{\mathrm{p}}{ }^{2}=.02$, the extent to which exclusion decreases recognition accuracy appears to be due to an increase in memory confusions rather than a general impairment on memory performance.

\section{Table 3}

Mean proportion of recognition responses in Experiment 3, (hit = correctly stating that a target word had described the target person; confusion = incorrectly stating that a lure word described the target person; false alarm = indicating that a new word had described the target person)

\begin{tabular}{lccc}
\hline & Exclusion 1 & Control & Exclusion 2 \\
\hline Hit & $0.61^{\mathrm{a}}(0.14)$ & $0.68^{\mathrm{b}}(0.11)$ & $0.70^{\mathrm{b}}(0.12)$ \\
Confusion & $0.49^{\mathrm{a}}(0.16)$ & $0.40^{\mathrm{b}}(0.13)$ & $0.33^{\mathrm{c}}(0.15)$ \\
False Alarm & $0.37^{\mathrm{a}}(0.15)$ & $0.38^{\mathrm{a}}(0.18)$ & $0.33^{\mathrm{a}}(0.15)$ \\
\hline
\end{tabular}

Note that participants in the Exclusion 1 and Control conditions carried out the recognition task for targets $\mathrm{T} 1$ and $\mathrm{T} 2$ (the two members of the central relationship) whereas participants in the Exclusion 2 condition carried out the task for targets T1 and T3 (one member of the central relationship and the person who had been excluded from it).

Means within a row marked with different superscripts are significantly different from each other $(p<.05)$. 


\section{Discussion}

Experiment 3 replicated Experiments $2 \mathrm{a}$ and $2 \mathrm{~b}$ by utilizing a memory confusion paradigm to investigate the extent to which participants' mental representations of individuals with different types of relationships overlap (i.e., are assimilated). If one's representations of two individuals overlap, one should be less able to distinguish between information related to one versus the other of them. Consistent with expectations, evidence was found for a greater degree of assimilation when the relationship excluded others than when it did not. This was indicated by a greater number of memory confusions in the exclusion condition than in the control condition.

On the other hand, participants formed relatively well-differentiated representations of two people who they viewed as being on opposite sides of the relationship boundary. When participants learned about one of the two relationship members along with a third person who had been actively excluded from the relationship, they made relatively few memory confusion errors. This suggests that participants were well able to distinguish between what they knew about the two targets.

Thus, these results support the hypothesis that social exclusion leads to assimilation of people in the exclusive relationship. When a boundary is recognized between two people in a relationship and others outside of it, one's representations of those people merge such that information processed in relation to one person is treated as if it applied to the other. These results are also consistent with those of the first experiment, which indicated that people perceive socially exclusive relationships as closer, more unique and more reciprocal, and members of such relationships as more similar.

In contrast, among participants in the exclusion 2 condition, the ability to distinguish between information learned about two targets was enhanced. This suggests that when the two targets fall on opposite sides of a boundary (e.g., one is included and one is excluded), those targets become more distinctive from each other. Again, this supports the idea that social exclusion leads to categorization, this time by demonstrating that contrast effects occur for individuals who are excluded.

\section{General discussion}

The experiments reported here support the hypothesis that perceivers use information regarding social exclusion to draw category boundaries between different sets of individuals. When two members of a relationship actively include another person in their interactions, that third person is included within the relationshipbased category. In contrast, and more interestingly, when the third person is actively prevented from joining the relationship, the category boundary is strengthened, with the excluded individual on the opposite side of the boundary. As a result of strengthening the category boundary, assimilation effects are more likely to occur. That is, the perceiver's representations of individuals within the relationship are more likely to merge.

In Experiment 1, perceivers' judgments about the closeness of various relationships reflected these processes. Participants consistently judged two individuals to be closer when they actively excluded others from their interactions, compared to when others were included in those interactions or were not mentioned at all. This pattern emerged despite the fact that the interactions themselves were identical across conditions-the only difference among conditions was whether a third person was or was not excluded from them. Thus, perceivers appear to use information about exclusion to draw inferences about interpersonal closeness. These inferences may be based upon the psychological distance of the perceivers' stored representations of relationship partners.
Experiments 2 and 3 provided more direct evidence about how relationships are represented in memory. When two individuals in a relationship socially exclude a third person, perceivers' representations of them become less differentiated, leading to a greater likelihood that information related to one relationship partner will be misattributed to the other. In contrast, the results of Experiment 3 suggested that representations of an excluded individual may become more differentiated from those of the relationship partners, leading to a lower likelihood of memory confusions involving the excluded individual.

The current work represents an initial foray into studying the consequences of exclusion for the mental representation of social relationships. While the topic of social exclusion has received substantial attention in recent years (e.g., Baumeister \& Tice, 1990; Baumeister, Twenge, \& Nuss, 2002; Eisenberger, Lieberman, \& Williams, 2003), this work has focused primarily on the consequences of exclusion for those who have been excluded. As argued at the outset of this paper, social exclusion may also play an important role in shaping our perceptions of other people's relationships. These perceptions may in turn have important consequences for our judgments and expectations of individuals involved in those relationships. Until now, this question has been neither asked nor answered in the psychological literature. Thus, the research presented here provides first insights into how impressions of social relationships are formed.

These studies raise further questions about the consequences of how relationships are represented. As suggested earlier, the perceived closeness of a relationship has repercussions for how we judge other aspects of the relationship. Experiment 1 suggests that, if a relationship is seen as particularly close, perceivers may judge its members to be more similar in terms of their personalities and social backgrounds. A related possibility is that closer relationships may be viewed as less permeable, which may influence our behavior towards members of the relationship. We may be less inclined to pursue or develop relationships with members of a relationship (whether it is a friendship or a romantic partnership) that is seen as exclusive, close, and impermeable. The question of whether socially exclusive relationships are viewed as not only closer but also less permeable is open to further investigation.

A further implication that bares consideration concerns the assumptions perceivers make about members of exclusive relationships. If relationship partners are presumed to share common characteristics-such as knowledge and goals-perceivers may hold one partner responsible for the actions of the other. Thus, the exclusiveness and consequent closeness of a relationship may influence judgments of collective responsibility (e.g., Lickel, Schmader, \& Hamilton, 2003) and assumptions about collective emotions (Lickel, Schmader, \& Barquissau, 2005).

\section{Is explicit exclusion necessary and sufficient?}

The theoretical framework adopted here suggests that the perception of social exclusion triggers a categorization process. This raises the question of whether exclusion, by itself, is sufficient to elicit categorization. To what extent need the individuals engaged in exclusion share a common bond independent of the act of exclusion? The data presented here do not directly address this question, as the perpetrators of exclusion were always members of a social relationship. However, recent research by Zadro, Williams, and Richardson (2005) has demonstrated that strangers who are induced to socially exclude another person develop greater feelings of closeness to each other (see discussion below). Thus, exclusion in the absence of pre-existing bonds may be sufficient to produce the effects described here.

Finally, there remain questions about what cues people use to determine whether social exclusion has taken place. In the studies 
reported here, exclusion is direct and explicit-there is little ambiguity about whether or not relationship partners have excluded someone else. However, there may be more subtle cues from which perceivers infer social exclusion. For example, observing that two individuals consistently share confidential information with each other may lead one to infer that they exclude others, because others are not explicitly included in their confidences. Further, perceivers may detect non-verbal cues that imply social exclusion, such as covert eye contact (i.e., two people taking sidelong glances at each other; see Kurzban, 2001) or speaking at low volumes to prevent others from overhearing.

\section{Exclusion and the self}

Social exclusion has been subject to social psychological study from a number of perspectives. For example, Baumeister, Williams, and colleagues (e.g., Baumeister \& Tice, 1990; Eisenberger et al., 2003) have generated a large body of research demonstrating various consequences of being socially excluded or ostracized. Although the bulk of this work concerns the experience of those who are targets of exclusion, Williams has suggested a number of motives for engaging in social exclusion. For example, social exclusion may be a tool used by individuals or groups to exert behavioral control on others (e.g., to punish deviant behavior). In addition, Kurzban and Leary's (2001) evolutionary approach argues that the social exclusion of individuals and groups may serve an adaptive function in that it allows people to avoid others who may be poor partners for social exchange or who may pose threats to our physical well-being. Though intriguing, neither analysis addresses the possible consequences of engaging in social exclusion for how one perceives and mentally represents one's own relationships from which others are excluded.

The data presented here, however, suggest clear predictions on this issue. If witnessing social exclusion by others leads to categorization of the individuals involved, it is perhaps even more likely that engaging in exclusion would do the same. Thus, one who actively excludes others from a relationship may experience greater intimacy with the other person in the relationship. In support of this notion, recent research from the author's laboratory suggests that leading individuals to view a friendship as exclusive has a direct effect on their experience of closeness within that relationship. In addition, Zadro et al. (2005) established that participants who role played an act of social exclusion reported, in some cases, greater feelings of belonging than did those who role played an act of inclusion or an act of verbal dispute. Thus, the social exclusion of others from one's relationships may serve the important function of increasing the extent to which one feels a bond with one's relationship partners.

\section{Mechanisms underlying exclusion effects}

A further question arising from this work concerns the stage at which categorization-based assimilation effects occur. In all studies presented in this paper, exclusion information was presented first, with memory and judgment measures collected later. Particularly in Experiments 2 and 3, this procedure ensured that categorization had taken place before further impressions of the target individuals had been formed. Thus, the assimilation of those individuals likely occurred prior to encoding the trait information about them. One potential criticism of this method is that participants were simply less motivated to discriminate between individuals who were included, which might call into question the conclusion that the patterns of memory confusions were due to assimilation.

This raises the question of how pre-existing representations (i.e., impressions of familiar others) are influenced by exclusion.
If exclusion leads to assimilation of those within a relationship, similar effects should be observable even when exclusion information is provided after impressions of the relevant individuals have been formed. This distinction provides an important direction for further research.

Finally, if exclusion information is an important cue to relationship and group membership, it may be transmitted in a number of ways, including those that extend beyond verbal communication. Particularly when communicating the exclusiveness of our own relationships, we may take advantage of other channels such as eye contact (mutual eye gaze as well as joint attention; e.g., Kurzban, 2001) and behavioural mimicry (e.g., Lakin \& Chartrand, 2003).

\section{Conclusions}

In sum, social exclusion provides important information about others'-and perhaps our own-relationships. Exclusion exerts a strong influence on how relationships are mentally represented. These representations may subsequently influence judgments of closeness along with other relationship characteristics, which may in turn have important consequences for how we as perceivers judge and behave towards members of those relationships.

\section{Acknowledgments}

The author thanks Guglielmo Calvini and several anonymous reviewers for their comments on an earlier version of this manuscript, and Julie Griffin for her assistance with data collection.

\section{References}

Abelson, R. P. (1983). Whatever became of consistency theory? Personality and Social Psychology Bulletin, 9, 37-64.

Altman, I., \& Taylor, D. A. (1973). Social penetration: The development of interpersonal relationships. Oxford, England: Holt, Rinehart \& Winston.

Anderson, N. H. (1968). Likableness ratings of 555 personality-trait words. Journal of Personality and Social Psychology, 9, 272-279.

Aron, A., \& Aron, E. (1986). Love and the expansion of self: Understanding attraction and satisfaction. New York: Hemisphere.

Aron, A., Melinat, E., Aron, E. N., Vallone, R., \& Bator, R. (1997). The experimental generation of interpersonal closeness: A procedure and some preliminary findings. Personality and Social Psychology Bulletin, 23, 363-377.

Aron, A., Norman, C. C., Aron, E. N., McKenna, C., \& Heyman, R. E. (2000). Couples' shared participation in novel and arousing activities and experienced relationship quality. Journal of Personality and Social Psychology, 78, 273-284.

Baumeister, R. F., \& Tice, D. M. (1990). Anxiety and social exclusion. Journal of Social and Clinical Psychology, 9, 165-195.

Baumeister, R. F., Twenge, J. M., \& Nuss, C. K. (2002). Effects of social exclusion on cognitive processes: Anticipated aloneness reduces intelligent thought. Journal of Personality and Social Psychology, 83, 817-827.

Blascovich, J., Wyer, N. A., Swart, L. A., \& Kibler, J. L. (1997). Racism and racial categorization. Journal of Personality and Social Psychology, 72, 1364-1372.

Castano, E., \& Yzerbyt, V. Y. (1998). The high and lows of group homo-geneity. Behavioural Processes, 42, 219-238.

Castano, E., Paladino, M. P., Coull, A., \& Yzerbyt, V. (2002). Protecting the ingroup stereotype: Ingroup identification and the management of deviant ingroup members. British Journal of Social Psychology, 41, 365-385.

Castano, E., Yzerbyt, V. Y., Bourguignon, D., \& Seron, E. (2002). Who may enter? The impact of ingroup identification on ingroup-outgroup categorization. Journal of Experimental Social Psychology, 38, 315-322.

Collins, N. L., \& Miller, L. C. (1994). Self-disclosure and liking: A meta-analytic review. Psychological Bulletin, 116, 457-475.

Corneille, O., \& Judd, C. M. (1999). Accentuation and sensitization effects in the categorization of multifaceted stimuli. Journal of Personality and Social Psychology, 77, 927-941.

Doise, W. (1990). Social biases in categorization processes. In J. M. Fabre \& J. P. Caverni (Eds.), Cognitive biases (pp. 305-323). Oxford, England: North-Holland.

Doosje, B., Haslam, S. A., Spears, R., Oakes, P. J., \& Koomen, W. (1998). The effect of comparative context on central tendency and variability judgments and the evaluation of group characteristics. European Journal of Social Psychology, 28, 173-184.

Eisenberger, N. I., Lieberman, M. D., \& Williams, K. D. (2003). Does rejection hurt? An fMRI study of social exclusion. Science, 302, 290-292.

Fine, G. A. (1977). Social components of children's gossip. Journal of Communication, 27, 181-185. 
Fraley, B., \& Aron, A. (2004). The effect of a shared humorous experience on closeness in initial encounters. Personal Relationships, 11, 61-78.

Hamilton, D. L., \& Sherman, S. J. (1996). Perceiving persons and groups. Psychological Review, 103, 336-355.

Heider, F. (1946). Attitudes and cognitive organization. Journal of Psychology: Interdisciplinary and Applied, 21, 107-112.

Jetten, J., Spears, R., \& Postmes, T. (2004). Intergroup distinctiveness and differentiation: A meta-analytic integration. Journal of Personality and Social Psychology, 86, 862-879.

Judd, C., \& Park, B. (1993). The assessment of accuracy of social stereotypes. Psychological Review, 100, 109-128.

Kurzban, R. (2001). The social psychophysics of cooperation: Nonverbal communication in a public goods game. Journal of Nonverbal Behavior, 25, 241-259.

Kurzban, R., \& Leary, M. R. (2001). Evolutionary origins of stigmatization: The functions of social exclusion. Psychological Bulletin, 127, 187-208.

Lakin, J. L., \& Chartrand, T. L. (2003). Using nonconscious behavioral mimicry to create affiliation and rapport. Psychological Science, 14, 334-339.

Lickel, B., Schmader, T. \& Barquissau, M. (2005). Aspects of social identity in the experience of collective guilt and shame. In N. R. Branscombe \& B. Doosje (Eds.), Collective guilt: International perspectives. New York: Cambridge University Press.

Lickel, B., Schmader, T., \& Hamilton, D. L. (2003). A case of collective responsibility: Who else was to blame for the Columbine High School shootings? Personality and Social Psychology Bulletin, 29, 194-204.

Long, K. M., \& Manstead, A. S. R. (1997). Group immersion and intergroup differentiation: Contextual shifts in categorization. British Journal of SocialPsychology, 36, 291-303.

Mashek, D. J., Aron, A., \& Boncimino, M. (2003). Confusions of self with close others Personality and Social Psychology Bulletin, 29, 382-392.

Murphy, G. L., \& Medin, D. L. (1985). The role of theories in conceptual coherence. Psychological Review, 92, 289-316.

Nelson, L. J., \& Miller, D. T. (1995). The distinctiveness effect in social categorization: You are what makes you unusual. Psychological Science, 6, 246-249.
Nosofsky, R. M. (1986). Attention, similarity, and the identification-categorization relationship. Journal of Experimental Psychology: General, 115, 39-57.

Pickett, C. L., \& Brewer, M. B. (2005). The role of exclusion in maintaining ingroup inclusion. In D. Abrams, M. A. Hogg, \& J. M. Marques (Eds.), The Social Psychology of Inclusion and Exclusion. New York: Psychology Press.

Rothbart, M., Davis-Stitt, C., \& Hill, J. (1997). Effects of arbitrarily placed category boundaries on similarity judgments. Journal of Experimental Social Psychology, 33, $122-145$.

Sedikides, C., Olsen, N., \& Reis, H. T. (1993). Relationships as natural categories. Journal of Personality and Social Psychology, 64, 71-82.

Simon, B., \& Brown, R. (1987). Perceived intragroup homogeneity in minority^majority contexts. Journal of Personality and Social Psychology, 53, 703-711.

Srull, T. K., \& Wyer, R. S. (1989). Person memory and judgment. Psychological Review, 96, 58-83.

Stangor, C., Lynch, L., Duan, C., \& Glass, B. (1992). Categorization of individuals on the basis of multiple social features. Journal of Personality and Social Psychology, $62,207-218$.

Tajfel, H., \& Turner, J. C. (1986). The social identity theory of inter-group behavior. In S. Worchel \& L. W. Austin (Eds.), Psychology of Intergroup Relations. Chigago: Nelson-Hall.

Taylor, S. E., Fiske, S. T., Etcoff, N. L., \& Ruderman, A. J. (1978). Categorical and contextual bases of person memory and stereotyping. Journal of Personality and Social Psychology, 36, 778-793.

Turner, J. C., Hogg, M. A., Oakes, P. J., Reicher, S. D., \& Wetherell, M. S. (1987) Rediscovering the social group: A self-categorization theory. Cambridge, MA, US: Basil Blackwell.

Tversky, A. (1977). Features of similarity. Psychological Review, 84, 327-352.

Yzerbyt, V. Y., Leyens, J-P., \& Bellour, F. (1995). The ingroup overexclusion effect: Identity concerns in decisions about group membership. European Journal of Social Psychology, 25, 1-16.

Zadro, L., Williams, K. D., \& Richardson, R. (2005). Riding the 'O' train: Comparing the effects of ostracism and verbal dispute on targets and sources. Group Processes and Interpersonal Relations, 8, 125-143. 